\title{
Migración internacional, economías familiares, mercados y medio ambiente en México
}

\author{
RAFAEL G. REYES MORALES* \\ ALICIA SYLVIA GIJÓN CRUZ** \\ ISABEL CRUZ HERNÁNDEZ***
}

RESUMEN: Se expone un modelo general de las economías de los hogares rurales de México que establece una relación entre el nivel de bienestar familiar y los ingresos de los hogares procedentes de la economía de mercado. Las remesas internacionales son parte de estos ingresos, y además se consideran transferencias de gobierno, producción de autoconsumo y disponibilidad de capital humano y social. Las remesas internacionales podrían ser el catalizador, y en otros casos los salarios regionales, para elevar el nivel de bienestar más allá del nivel que permite alcanzar la economía local a la gran mayoría de los hogares. Sin embargo, el nivel de bienestar familiar se puede erosionar por un incremento en el gasto en salud debido a la contaminación ambiental y dietas desequilibradas. Cuando esto ocurre, los hogares habrán rebasado su nivel de consumo crítico y entonces cualquier incremento en el ingreso familiar producirá niveles decrecientes de bienestar familiar.

PALABRAS CLAVE: bienestar familiar, remesas internacionales, salarios regionales, capital social y humano, consumo crítico.

* Profesor investigador del Instituto Tecnológico de Oaxaca, México.

** Profesora de la Universidad Autónoma Benito Juárez de Oaxaca, México.

*** Directora general de la Asociación Mexicana de Uniones de Crédito del Sector Social, México. 
ABSTRACT: This article describes a general economic model of rural households in Mexico that establishes a relationship between the degree of family wellbeing and the household incomes drawn from the market economy. International remittances are a part of these incomes, as well as: government payments, production for household consumption, and the availability of human and social capital. International remittances could be viewed as the catalyst, and in other cases regional wages, to raise the levels of wellbeing beyond the level that allows for the majority of households to participate in the local economy. However, the level of family wellbeing may be eroded incrementally by deteriorating health indicators due to environmental contamination and insufficient diets. When this occurs, households will have surpassed critical consumption levels and therefore any increase in family income will still lead to decreasing levels of family wellbeing.

KEY wORDS: family wellbeing, international remittances, regional wages, social and human capital, critical consumption.

$118 \frac{\text { SEGUNDO SEMESTRE } 2015}{\text { MIGRACIÓN Y DESARROLLO NÚM. } 25}$ 


\section{INTRODUCCIÓN}

E n este trabajo se presenta y se prueba un modelo general de las economías de los hogares rurales que establece una relación entre el nivel de bienestar familiar y los ingresos obtenidos de la economía de mercado, la producción de autoconsumo, las transferencias del gobierno y otros hogares. Esta relación está sujeta a, por un lado, la disponibilidad de capital humano y social en los hogares cuya intensidad puede contribuir a elevar el nivel del bienestar familiar y, por otro lado, los efectos adversos de la contaminación y las dietas desequilibradas que contraen el nivel de bienestar familiar. Esta es la hipótesis del trabajo que se probará con los resultados de dos estudios realizados en cuatro comunidades de tres estados de la República Mexicana.

Las remesas internacionales podrían ser el catalizador y en otros casos los salarios regionales para elevar el nivel de bienestar familiar más allá de la capacidad de las economías locales. Se consideran todas las posibles estrategias de los hogares para obtener ingresos monetarios y no monetarios. El bienestar familiar se define exhaustivamente por rubros de gastos de los hogares en un intervalo que va desde un nivel de consumo mínimo (subsistencia) a un nivel de consumo máximo o crítico. Un incremento en el ingreso familiar se reflejará en un incremento proporcional en el consumo, el cual será a proximadamente igual al bienestar familiar. Cuando se rebase el nivel de consumo crítico, los incrementos en el ingreso familiar y, consecuentemente en el consumo, producirán niveles decrecientes de bienestar familiar. Esto se debe a los efectos negativos en la salud por la contaminación producida en los hogares y las dietas desequilibradas en presencia de enfermedades crónico-degenerativas.

El modelo de bienestar familiar permite analizar las condiciones que favorecen o restringen la migración internacional, la cual puede ser considerablemente alta aun en las zonas de agricultura comercial de altos rendimientos. Especialmente cuando el mercado de productos agrícolas se encuentra controlado por acaparadores y los productores están a merced de la delincuencia organizada. Por el contrario, la migración internacional 
puede ser sustituida por salarios regionales y un mercado local. Incluso el aislamiento, la existencia de un cultivo comercial en pequeña escala y un mercado local pueden ser suficientes para evitar o controlar la migración internacional. Otras veces, la migración interna puede ser una buena alternativa a la tentación de involucrarse en la producción de «cultivos de alto riesgo» o a la riesgosa aventura de la migración internacional indocumentada.

Los resultados de este trabajo muestran que es posible eliminar la migración de fuerza laboral a otras partes de México y al extranjero mediante la inversión permanente en educación para aprovechar la oferta de salarios de los mercados laborales regionales. De esta manera, se pueden traer ingresos a casa sin tener que cambiar de residencia y además los excedentes monetarios se pueden invertir localmente en negocios familiares y actividades agropecuarias; esto permitirá, a su vez, crear mercados laborales, de bienes y servicios.

Una lección aprendida en este trabajo es que cuando se elimina la migración internacional, la atención se centra en los problemas de salud asociados a la contaminación de cuerpos de agua y a las dietas desequilibradas. El lector podrá ver a la migración internacional por medio del modelo de bienestar familiar desde una perspectiva multidisciplinaria con datos primarios de campo y laboratorio. La teoría económica, por ejemplo, permite analizar el papel de las remesas internacionales con la participación de las instituciones financieras en la economía de los hogares rurales frente a otras estrategias para obtener ingresos.

\section{BASES TEÓRICAS Y METODOLÓGICAS DEL MODELO}

\section{Enfoque del bienestar familiar}

Sen (1999) define el bienestar en términos de capacidades conformadas por todo aquello que permite a una persona estar bien nutrida, escribir, leer y comunicarse. Las necesidades básicas constituyen una parte de las capacidades;

$120 \frac{\text { SEGUNDO SEMESTRE } 2015}{\text { MIGRACIÓN Y DESARROLLO NÚM. } 25}$ 
el número de opciones que las personas tienen y la libertad de elección sobre ellas también contribuyen al bienestar humano. Las capacidades a desarrollar dependen del ámbito en el que se desenvuelvan y la libertad con la que cuenten. Entre las restricciones que deben eliminarse para que la población tenga mayor libertad están las escasas oportunidades económicas, privaciones sociales sistemáticas, falta de servicios públicos y la intolerante actuación de los Estados-nación. Este es el caso de la población pobre que se enfrenta a mayores restricciones en el desempeño laboral sin recibir prestaciones, incentivos en el trabajo, ni un salario adecuado acorde con las labores que desempeña. Si no se dispone de acceso a los servicios públicos, como drenaje, energía eléctrica y agua, disminuyen las probabilidades de que este estrato de la población desarrolle sus capacidades en el ámbito laboral y en la educación de los hijos. La falta de alimentos para el sustento de la familia origina que los pobres se encuentren más propensos a enfermedades, ya sea por alguna deficiencia nutricional o por la falta de servicios, provocándoles enfermedades gastrointestinales y respiratorias. En síntesis, Sen (1999) visualiza la pobreza como la privación de capacidades básicas y no solamente como la falta de ingresos, que es el criterio habitual con que se identifica la pobreza. Boltvinik (2003) coincide con Sen en el análisis de la relación entre bienestar y pobreza. La pobreza para este autor es un proceso multidimensional en el que el bienestar de los hogares y las personas depende de seis fuentes: i) ingreso corriente; ii) activos no básicos y capacidad de endeudamiento del hogar; iii) patrimonio familiar; iv) acceso a bienes y servicios gratuitos; v) tiempo libre y disponible para trabajo doméstico, educación y reposo, y vi) conocimientos de las personas. Los primeros tres los llama recursos económicos privados (monetarios); la cuarta fuente representa los recursos económicos públicos o «salario social»; las dos últimas son el recurso humano y el recurso tiempo. Por tanto, para tener bienestar en los hogares es importante considerar varios factores que influyen de manera negativa en las unidades familiares, pero el ingreso es el determinante principal. Si brinda preferencia al trabajo para obtener ingresos, puede descuidarse la salud o la educación. El enfoque de estos autores trata de explicar el bienestar de los hogares de un país en relación con el papel del Estado nacional, mientras que los miembros del hogar juegan un papel pasivo. 
A diferencia de estos autores, el enfoque de este trabajo se basa en un modelo de bienestar familiar que explica de manera consistente, desde la economía de los hogares, la relación entre el bienestar familiar y los factores que lo determinan en varios ámbitos, esto es, el hogar, la economía local y los vínculos con la región, el resto del país y otros países (Reyes y Gijón, 2011 y 2012). El concepto de bienestar que se utilizará en este trabajo se refiere al modelo de bienestar familiar que se alimenta de información producto del consenso y el esfuerzo de los miembros de los hogares. En trabajos anteriores se probó que puede intercambiarse el bienestar familiar $(B F)$ por el componente de gasto en salud (GS) y además pueden internalizarse los costos de la contaminación química y biológica de cuerpos de agua y suelo, así como los de dietas ricas en carbohidratos (Celaya, 2013; Benítez, 2013; Pacheco, 2013). Una discusión formal sobre la internalización de costos aparece en Reyes Morales y Gijón Cruz (2013). Las enfermedades y las dietas se incorporan como variables dicotómicas, mientras la contaminación se mide cuantitativamente utilizando técnicas de laboratorio. El GS aparecerá en lugar de BF para magnificar el costo del tratamiento de enfermedades y el efecto de la dieta.

En relación con la corriente denominada «la nueva teoría económica de la migración laboral», a la cual debemos parte del instrumental metodológico, ${ }^{1}$ nuestra propuesta ofrece un concepto más acabado del bienestar familiar, que el expuesto por Taylory Yúnez (1999). Estos autores abordan el concepto de bienestar familiar a través de modelos de hogares agrícolas para las condiciones específicas de la agricultura en México. El bienestar aparece de manera implícita en la relación entre educación y migración internacional, la cual determina el incremento en la productividad agrícola. Antes, Strauss (1986) había asociado el bienestar con el consumo de calorías como medio para explicar la productividad agrícola. En cambio, el modelo de bienestar familiar define el bienestar en forma más amplia y exhaustiva por medio de

${ }^{1}$ En particular, se puede señalar la primera versión del cuestionario de la encuesta y la metodología para construir las matrices de contabilidad social.

$122 \frac{\text { SEGUNDO SEMESTRE } 2015}{\text { MIGRACIÓN Y DESARROLLO NÚM. } 25}$ 
la economía familiar y sus vinculaciones con la economía local y con los mercados externos.

Participación de las economías familiares en la economía de mercado

El ingreso familiar (IF) representa la suma de los ingresos del hogar obtenidos por la participación de sus miembros en la economía de mercado, actividades de autoconsumo y la recepción de transferencias. Los hogares obtienen salarios locales $(S L)$ y salarios regionales $(S R)$ por la venta de su mano de obra en los mercados laborales, local y regional sin tener que cambiar de domicilio. Otras veces la fuerza de trabajo familiar tiene que emigrar para obtener remesas internas $(R N)$ en los mercados laborales nacionales y remesas internacionales $(R I)$ en los mercados laborales de Estados Unidos. La venta de excedentes de la producción familiar en los mercados de bienes y servicios aporta a los hogares utilidades $(U)$. Otras formas de ingresos monetarios se obtienen de los mercados financieros a través de préstamos (Pr), el cobro de intereses (ICID) o retiros del monto de los ahorros familiares que están depositados en las instituciones financieras $(R A h)$.

El IF tiene dos componentes, uno relativo a los ingresos obtenidos por participar en la economía de mercado (mercados: laboral, financiero, de bienes y servicios), que se le denominará ingreso familiar productivo (IFP), esto es, la suma de los ingresos señalados arriba: $S L+S R+R N+R I+U+$ $\mathrm{Pr}+I C I D+R A h$. El otro componente del IF se refiere a las transferencias obtenidas del gobierno y de otros hogares. El gobierno mexicano empezó a realizar transferencias en efectivo y en especie $(T G)$ a los hogares vulnerables para compensar su bajo poder adquisitivo y para asegurar su integración a la economía de mercado con los primeros gobiernos posrevolucionarios. La sociedad mexicana dispone de prácticas sociales e instituciones comunitarias de ayuda mutua que son el resultado de la amalgama de las culturas indígenas prehispánicas y la cultura española. En el crisol que dio origen a esta amalgama, la religión católica ha sido el elemento aglutinador. La parte medible monetariamente de estas prácticas sociales son las transferencias en efectivo 
y en especie que los hogares reciben de otros hogares (TOH). El IF se define a través de los ingresos obtenidos de la economía de mercado y las transferencias; y se puede expresar mediante la siguiente ecuación:

$$
I F=S L+S R+R N+R I+U+P r+I C I D+R A h+T G+T O H
$$

La fuerza laboral familiar posee características socioeconómicas que le permiten ser más competitiva o bien pueden actuar como restricciones para obtener ingresos, tales como edad (Ed), sexo (Sex), escolaridad (Esc), ocupación $(O c)$, condición de migrante ( $M i g)$, tamaño de la fuerza laboral (TFL), número de migrantes (NM). Además, habrá que considerar el tamaño del hogar o número de miembros del hogar $(T H)$. La producción familiar requiere también de la fuerza laboral, de la mano de obra de tiempo parcial de otros miembros del hogar (niños, personas de la tercera edad y mujeres normalmente dedicadas a labores domésticas). Estos miembros, al igual que la fuerza laboral, están considerados en el TH. El conjunto de estas características ayudan al hogar a obtener un determinado nivel de ingresos. A esta capacidad general de los hogares para obtener ingresos se le denominará en este trabajo capital humano.

La variable TOH es una medida monetaria de capital social y se encuentra ligada principalmente a la religión ( $\operatorname{Rel} \mathrm{C} a$ ) por medio del compadrazgo cuya red de relaciones se afianzan a través de bautizos, bodas, primera comunión, confirmación, quince años. La religión refuerza las relaciones de intercambio de regalos y de trabajo que se llevan a cabo en las redes familiares, de paisanos y amigos. A nivel de la comunidad, las redes de intercambio se aglutinan por las mayordomías de las fiestas patronales, el sistema de cargos y clubes de migrantes ubicados en otras ciudades del país o en el extranjero. Estos elementos definen, a su vez, la identidad comunitaria y ésta adquiere normalmente mayores dimensiones en las comunidades indígenas. Por lo tanto, se puede utilizar como indicador de identidad étnica a los hogares hablantes de una lengua indígena (HogHLI). Finalmente, la ecuación de IF se puede expresar mediante la ecuación [1.2]. Cuando se incorporan a la ecuación [1.1] las variables de capital humano y capital social, es necesario 
multiplicar por un coeficiente $a_{i}$ todas las variables que forman la ecuación. De esta manera, se podrá realizar la suma algebraica de variables con diferentes unidades de medición.

$$
\begin{gathered}
I F=a_{1} S L+a_{2} S R+a_{3} R N+a_{4} R I+a_{5} U+a_{6} P r+a_{7} I C I D+a_{8} R A h+ \\
a_{9} T G+a_{10} T O H \pm\left(a_{11} E d+a_{12} S e x+a_{13} E s c+a_{14} O c+a_{15} M i g\right. \\
\left.+A_{16} T F L+a_{17} N M\right)+a_{18} R e l C a+a_{18} H o g H L I
\end{gathered}
$$

Bienestar familiar con internalización de costos ambientales

La ecuación [1.1] explica el nivel de IF obtenido por la participación de la fuerza laboral familiar en la economía de mercado y por las transferencias recibidas del gobierno y de la sociedad. Las variables de capital humano y de capital social (con excepción de TOH que está dada en unidades monetarias) que aparecen en la ecuación [1.2] permiten explicar únicamente los niveles obtenidos de $I F$, ya que su inclusión no aporta ingresos monetarios.

Antes de continuar es necesario definir el bienestar familiar $(B F)$ : constituye la meta global de los hogares y el incentivo que anima la actividad económica. Cuando los hogares hacen uso de su presupuesto familiar dado por $I F$, una parte de éste se asignará al consumo $(C)$, otra más se ahorra en instituciones financieras o en tandas $(A h)$ y la última fracción se destina a la inversión en un negocio familiar o la producción de autoconsumo (Inv). Así, se obtiene otra ecuación del $I F$ dada por [1.3].

El bienestar familiar $(B F)$ se puede medir mediante el presupuesto familiar asignado al consumo $(C)$ a través de la ecuación [1.4] que se obtiene despejando esta variable de la ecuación [1.3]. Para que la expresión $C \cong B F$ se cumpla, la estructura de gastos de los hogares debe ser lo suficientemente amplia para cubrir no sólo el consumo necesario que asegure la supervivencia biológica, sino también para cubrir el consumo de confort, calidad y esparcimiento; e incluso debe ser suficiente para hacer transferencias a otros hogares. 


$$
\begin{gathered}
I F=C+A+\operatorname{Inv} \\
B F \cong C=I F-(A+\operatorname{Inv})
\end{gathered}
$$

La primera categoría de consumo es la básica o de subsistencia, ya que provee a los miembros de los hogares los siguientes satisfactores: alimentación, ropa y calzado, acceso a la vivienda y a los servicios básicos de ésta, a los servicios de salud, educación y transporte. Los hogares más pobres pueden vivir con estos satisfactores y además podrán convivir con el resto de la sociedad civilizada. Conforme el IF se incrementa, los hogares pueden pagar otros satisfactores que proporcionan confort y esparcimiento (muebles, aparatos electrodomésticos, aparatos de comunicaciones y esparcimiento; servicios pagados de televisión, internet, telefonía fija y móvil; fiestas y vacaciones; vehículos, mejoramiento de su vivienda; seguros de vida y automóviles, tenencia de automóviles). No obstante, varios de estos satisfactores ya son parte de la vida cotidiana de los hogares más pobres de la sociedad mexicana, debido al efecto abrumador de los medios masivos de comunicación en prácticamente todo el territorio nacional. La participación de los miembros de la fuerza laboral en mercados laborales nacionales e internacionales también contribuye a incrementar el consumo en los hogares de origen. Los satisfactores que proporcionan confort y esparcimiento están orientados a elevar la calidad de vida de los hogares y el prestigio social. El $B F$ como sinónimo de calidad de vida incluye, además, una dieta equilibrada en nutrientes. Rubros de consumo tales como vivienda y vehículos, adquirirán relevancia porque se convertirán en activos que engrosarán el patrimonio familiar.

El excedente de IF permitirá, además del ahorro y la inversión, la prácticas sociales de ayuda mutua, que es un valor social inmanente de la sociedad mexicana de todos los estratos sociales. Este último constituye una fuente de ingreso de la economía familiar que normalmente no se considera en la teoría económica. En realidad, este componente de IF es de carácter recíproco y representa un gasto cuando el hogar lo otorga, en este caso, forma parte del $B F$ porque produce satisfacción de manera similar a una rica comida, a la experiencia de disfrutar una película en los cómodos muebles de la sala.

$126 \frac{\text { SEGUNDO SEMESTRE } 2015}{\text { MIGRACIÓN Y DESARROLLO NÚM. } 25}$ 
La ecuación de consumo se puede utilizar para medir el bienestar familiar $(B F)$ en un intervalo de consumo cuyos extremos son un nivel mínimo de consumo que asegura la supervivencia de los hogares $\left(C_{\text {Min }}\right)$ y un nivel máximo o crítico de consumo $\left(C_{\text {Critico }}\right)$. Es decir, el $B F$ está definido en el intervalo $C_{\text {Min }} \leq B F \leq C_{\text {Crítico }}$ y la relación funcional entre $B F$ e $I F$ es directa. Un incremento en el consumo más allá del $C_{\text {Critico invertirá el sentido de la rela- }}$ ción entre $B F$ e IF. Es decir, cualquier incremento en el IF más allá de $C_{\text {Critico }}$ producirá niveles de calidad de vida decrecientes. La contaminación ambiental producida por los hogares y una dieta desequilibrada pueden incrementar considerablemente el gasto en salud, así como en general un exceso de consumo puede producir endeudamiento y, en consecuencia, disminuir los rubros de gasto en calidad de vida. Estos factores pueden hacer que el consumo de los hogares rebase el $C_{\text {Crtitico. }}$. 1 l $B F$ debe considerar no sólo movimientos ascendentes de IF, Ah e Inv dados por [1.4], sino también los costos ambientales, CCA y aquellos asociados a malos hábitos de alimentación, $\mathrm{CMH}$ :

$$
\begin{gathered}
B F=a_{1} S L+a_{2} S R+a_{3} R N+a_{4} R I+a_{5} U+a_{6} P r+a_{7} I C I D+a_{8} R A h+ \\
a_{9} T G+a_{10} T O H \pm\left(a_{11} E d+a_{12} S e x+a_{13} E S C+a_{14} O c+a_{15} M i g+A_{16} T F L+a_{17} N M\right)+ \\
a_{18} R e l C a+a_{19} H o g H L I-\left(\alpha_{20} C C A+\alpha_{21} C M H\right)
\end{gathered}
$$

\section{Migración internacional Y MERCADOS local Y REgional}

Se presentan los resultados de un estudio realizado en tres localidades rurales de los estados de Michoacán, Guerrero y Oaxaca con acceso a servicios financieros (La Purísima, San Miguel Totolapa y San Agustín Loxicha, respectivamente). Estas localidades han adoptado estrategias relativamente exitosas para afianzar su desarrollo económico de acuerdo con los recursos disponibles y el acceso a los mercados. Cada localidad se ha integrado a las economías nacional e internacional mediante diferentes estrategias, las cuales han permitido delinear una red de relaciones económicas regionales específicas. El aislamiento geográfico y el blindaje de los comerciantes y 
otros emprendedores locales para protegerse de los mercados regionales han sido determinantes en la conformación de un mercado local. Por el contrario, la integración a los mercados regionales mediante rápidas vías de comunicación puede convertirse en una restricción para desarrollar el mercado local. De la misma manera, la migración internacional laboral puede apoyar el desarrollo de un mercado local, si existe en él una actividad comercial preponderante y acceso al mercado regional. Las tres localidades permitirán ilustrar la difícil tarea que implica el desarrollo local, es decir, no sólo se muestran estrategias acertadas en condiciones de aislamiento y escasez de recursos, sino también las restricciones que enfrentan los excedentes de la pequeña producción en el mercado regional, incluyendo la delincuencia organizada.

Economias familiares rurales, remesas internacionales y servicios financieros

Características de las localidades de estudio y su región económica. La Purísima es una comunidad que produce maíz, con una de las más altas productividades en México y con ganadería comercial en pequeña escala. Esta comunidad se formó en los años treinta como resultado del reparto de las tierras de la hacienda cuya patrona es la Virgen de la Purísima Concepción. Se localiza a cuatro kilómetros del aeropuerto internacional de la ciudad de Morelia y a 26 kilómetros de esta ciudad. El municipio de Álvaro Obregón al que pertenece La Purísima tiene su origen en las haciendas creadas en la segunda mitad del siglo XVIII por la Iglesia católica, aunque el estatus de municipio fue alcanzado hasta 1930 (Inafed, Gobierno del Estado de Michoacán, 2009). La región o espacio de relaciones económicas de La Purísima la integran principalmente tres localidades: la cabecera municipal de Álvaro Obregón, Tzintzimeo y la cabecera del municipio de Zinapécuaro. Existe una fuerte relación económica con estas comunidades a través del intercambio de bienes y servicios. La Purísima vende su producción agrícola en estas tres localidades a los acaparadores regionales, quienes también controlan los servicios de cosecha mecánica y procesamiento, crédito y venta de insumos para la pro-

$128 \frac{\text { SEGUNDO SEMESTRE } 2015}{\text { MIGRACIÓN Y DESARROLLO NÚM. } 25}$ 
ducción. La cabecera municipal constituye el principal mercado de bienes y servicios de los hogares de La Purísima. En especial, se ofrecen servicios financieros por medio de bancos, cajas de ahorro, un microbanco de la Asociación Mexicana de Uniones de Crédito del Sector Social (AmUCSS), ${ }^{2}$ venta de maquinaria, equipo y refacciones.

San Miguel Totolapa es una comunidad indígena nahua, cuyo origen parece estar ligado a los 16 pueblos o estancias identificados a mediados del siglo XVI como parte de la República de Indios de Huamuxtitlán (Durand, Velásquez y Rodríguez, 2006). Sus terrenos son de propiedad comunal, como los de los demás pueblos indígenas del estado de Guerrero y en particular aquellos de la región de la Montaña (Sánchez Serrano, 2003). Estos terrenos se empezaron a repartir a los pueblos indígenas en la segunda mitad del siglo xvi durante la administración de los mixtecos, y la dotación fue de terrenos cubiertos con bosque ubicados en laderas con pendientes pronunciadas (Cervantes y De Teresa Ochoa, 2004). San Miguel Totolapa es la segunda localidad más grande del municipio de Huamuxtitlán, Guerrero, el cual alcanzó el estatus de municipio en 1850 (Inafed, Gobierno del Estado de Guerrero, 2009). Los comerciantes locales intentan reducir al mínimo la dependencia comercial con Tlapa de Comonfort, el mayor centro urbano de la región de Huamuxtitlán, la cabecera municipal y de Tulcingo del Valle, el centro urbano más cercano del estado de Puebla. En estas pequeñas ciudades no sólo se pueden adquirir bienes sofisticados, sino también se ofrece una amplia gama de servicios financieros. La oferta local de bienes y servicios de San Miguel Totolapa compite con las de estas ciudades en precios y además la gente no tiene que gastar dinero y tiempo adicional en transporte. La infraestructura local del comercio y los servicios la forman 30 tiendas de abarrotes, tres papelerías, una tlapalería, cinco tiendas de ropa y regalos, una tienda de materiales de construcción, dos mueblerías, dos fondas, tres estéticas o peluquerías, una sucursal de un microbanco de AmUCSS, ocho carnicerías o pollerías, dos casetas telefónicas, tres establecimientos que rentan películas

${ }^{2}$ Un microbanco es una institución microfinanciera rural que ofrece servicios integrales cuya metodología fue creada por la AmUCss. 
y juegos de video. Además, existen negocios que elaboran manufacturas en pequeña escala (dos de puertas, ventanas y cancelería de hierro y aluminio; una carpintería, una tortillería, 10 molinos de nixtamal); y también se elaboran productos artesanales (seis familias confeccionan ropa; cinco mujeres elaboran y venden tortillas; y la mayoría de las mujeres bordan servilletas). El relativo aislamiento de San Miguel Totolapa ubicado en la cañada de Huamuxtitlán permite a los negocios locales cubrir casi en su totalidad la demanda de bienes y servicios de los hogares. Sin embargo, los servicios financieros aún no cubren las necesidades y expectativas de los hogares. Existe una fuerte relación comercial con otras ciudades del estado de Puebla (Izúcar de Matamoros, Atlixco y Puebla) y con la Ciudad de México. Los comerciantes locales adquieren los insumos que requieren para sus negocios en estas ciudades y específicamente en Atlixco, en donde se venden las servilletas bordadas (Entrevista a las autoridades locales). San Miguel Totolapa se encuentra ligada por medio del comercio con varios mercados nacionales como resultado de los esfuerzos de sus comerciantes para reducir la dependencia de los mercados regionales y para colocar su producción artesanal.

San Agustín Loxicha es la cabecera del municipio del mismo nombre y adquirió el estatus de ayuntamiento desde 1700; se encuentra ubicada en la vertiente del Pacífico de la Sierra Sur a 180 kilómetros de la ciudad de Oaxaca, la capital del estado. La emergencia del Ejército Popular Revolucionario (EPR) entre 1994 y 1996 ha dado fama nacional e internacional a este municipio (Inafed, Gobierno del Estado de Oaxaca, 2009). Los principales cultivos son el café, cultivo comercial en pequeña escala, y el maíz, el básico principal de autoconsumo que utiliza para su producción mano de obra familiar. San Agustín Loxicha introdujo el cultivo de café en 1854 (Salinas, 2000). La mejor época del café en México estuvo ligada al Instituto Mexicano del Café (Inmecafé) (1959-1989) y desde 1989 la Coordinadora Estatal de Productores de Café de Oaxaca (CEPCO) ha tratado de llenar el vacío que dejó el Estado mexicano entre los pequeños productores de café para aminorar los efectos del derrumbe cíclico del precio internacional en el estado de Oaxaca (Salinas, 2000; Aranda y Morales, 2002). La CEPCO ha adoptado las estrate-

$130 \frac{\text { SEGUNDO SEMESTRE } 2015}{\text { MIGRACIÓN Y DESARROLLO NÚM. } 25}$ 
gias de «comercio justo» $y$ de «cafés especiales» para negociar buenos precios para el café oaxaqueño en Europa y además ofrece crédito a los productores de café afiliados a través de la Unión de Crédito Estatal de Productores de Café de Oaxaca (UCEPCO). San Agustín Loxicha se encuentra entre los municipios agremiados, con una marca de denominación de origen de su café. La región económica de la localidad de San Agustín Loxicha la integran las 61 localidades ubicadas en su territorio municipal que acuden a comprar los domingos al tianguis. En forma permanente se ofertan bienes y servicios por medio de 20 tiendas de abarrotes, tres papelerías, tres carnicerías, dos establecimientos de frutas y verduras, tres ferreterías o tlapalerías, tres tiendas de ropa, tres depósitos de cervezas, cuatro farmacias, tres tiendas de materiales de construcción, una tienda Diconsa del gobierno federal, una panadería, cuatro fondas, dos hoteles, una estética, dos talleres mecánicos, un taller de reparación de electrodomésticos, dos cajas de ahorros, una sucursal de un microbanco de Amucss, un negocio de renta de películas y juegos de video, tres casetas telefónicas y un negocio de internet público. Asimismo, se producen algunas manufacturas en pequeña escala y productos artesanales en tres talleres que fabrican puertas, ventanas y cancelería de hierro y aluminio; cuatro carpinterías, cuatro molinos de nixtamal y cuatro negocios familiares que confeccionan ropa (Entrevistas a las autoridades municipales durante 2009).

Algunos habitantes de esta localidad hacen compras también en Miahuatlán de Porfirio Díaz, el centro urbano más cercano que oferta una amplia variedad de bienes y servicios. Los dueños de negocios también compran insumos en esta ciudad y en las ciudades de Oaxaca y Puebla. En las dos primeras se realizan gestiones en oficinas de los gobiernos estatal y federal, operaciones financieras. En síntesis, la región económica de San Agustín Loxicha la constituyen principalmente su tianguis dominical y los negocios permanentes, las localidades que acuden a comprar y Miahuatlán de Porfirio Díaz. Las ciudades de Oaxaca y Puebla proveen a San Agustín Loxicha de insumos para sus negocios, mientras que CEPCO constituye su principal comprador de café y su filial uCEPCo la fuente de crédito para la producción de este cultivo. 
Modelo de las economías familiares. Se levantó una encuesta probabilística en las comunidades San Miguel Totolapa y La Purísima durante 2008 y se concluyó en San Agustín Loxicha en 2009. De la base de datos de la encuesta se obtuvo la ecuación de regresión [2.1] la cual contiene seis variables independientes y un coeficiente de determinación, $\mathrm{R}^{2}$, de 0.712 (véase cuadro 1).

$$
\begin{gathered}
B F=1,626.865 T H+0.867 R I+1.44 P r+2.296 A h+0.454 U N C S+0.497 U N M A \\
(0.000) \\
(0.000)
\end{gathered}
$$

\section{CUADRO 1}

Resultados del análisis de regresión de mínimos cuadrados ordinarios del modelo de las economías familiares de La Purísima, San Miguel Totolapa

\begin{tabular}{|c|c|c|c|c|}
\hline & \multicolumn{2}{|c|}{ COEFICIENTES DE REGRESIÓN } & \multirow[b]{2}{*}{$\begin{array}{l}\text { ESTADÍSTICO DE LA } \\
\text { PRUEBA T DE STUDENT }\end{array}$} & \multirow[b]{2}{*}{ SIGNIFICACIÓN ${ }^{b}$} \\
\hline & $\begin{array}{c}\text { NO ESTANDARIZADOS } \\
\text { B }\end{array}$ & $\begin{array}{c}\text { ESTANDARIZADOS } \\
\beta\end{array}$ & & \\
\hline Tamaño del hogar, $T H$ & $1,626.865$ & 0.490 & 6.876 & 0.000 \\
\hline Remesas internacionales, $R I$ & 0.867 & 0.253 & 3.928 & 0.000 \\
\hline $\begin{array}{l}\text { Préstamos recibidos por los } \\
\text { hogares de cajas de ahorro y } \\
\text { bancos, } P r\end{array}$ & 1.44 & 0.183 & 2.876 & 0.005 \\
\hline $\begin{array}{l}\text { Ahorro depositado en cajas de } \\
\text { ahorro regionales, } A h\end{array}$ & 2.296 & 0.159 & 2.587 & 0.011 \\
\hline $\begin{array}{l}\text { Utilidades de negocios comer- } \\
\text { ciales y de servicios, UNCS }\end{array}$ & 0.454 & 0.157 & 2.36 & 0.021 \\
\hline $\begin{array}{l}\text { Utilidades de negocios de ma- } \\
\text { nufactura y artesanías, UNMA }\end{array}$ & 0.497 & 0.149 & 2.382 & 0.019 \\
\hline $\mathrm{R}^{2}$ & \multicolumn{4}{|c|}{0.712} \\
\hline $\mathrm{R}^{2}$ corregida & \multicolumn{4}{|c|}{0.691} \\
\hline F-estadística (Anova) & \multicolumn{4}{|c|}{$34.215, p<0.000$} \\
\hline $\begin{array}{l}\text { Grados de libertad (regresión y } \\
\text { residuales) }\end{array}$ & \multicolumn{4}{|c|}{6 y 83} \\
\hline
\end{tabular}
y San Agustín Loxicha ${ }^{a}$

a Se consideraron precios corrientes, ya que la diferencia entre el levantamiento de la encuesta en San Miguel Totolapa y La Purísima en relación con San Agustín Loxicha fue menor a un año. ${ }^{b}$ La significación de los coeficientes de regresión B se evaluó con respecto a la prueba t student, excepto para la F estadística en la cual se consideró una distribución F. 
El término constante de la ecuación [2.1] resultó ser nulo y la mejor ecuación de regresión con término constante diferente de cero tiene una $\mathrm{R}^{2}$ de apenas 0.291, por esta razón, se descartó esta última ecuación. Las variables independientes ordenadas de acuerdo con sus pesos en la ecuación, $\beta_{q}$, son (Knoke, Bohrnstedt y Potter, 2002): ${ }^{3}$ tamaño del hogar, $T H\left(\beta_{1}=0.490\right)$; remesas internacionales, $R I\left(\beta_{2}=0.253\right)$; préstamos, $\operatorname{Pr}\left(\beta_{3}=0.183\right)$; ahorro, $A h\left(\beta_{4}=0.159\right)$; utilidades de negocios comerciales y de servicios, UNCS ( $\beta_{5}$ $=0.157)$, y utilidades de negocios de manufacturas y artesanías, UNMA $\left(\beta_{6}=0.149\right)$. Debajo de cada término de la ecuación [2.1] aparece el valor de la significación de la prueba t de student. Se puede decir que esta ecuación es estadísticamente consistente, ya que supera la prueba del análisis general de varianza de la ecuación, es decir, F = 34.215 es significativa $(p<0.000)$, y cada coeficiente de regresión no estandarizado B supera la prueba $t$ de student al menos para $p<0.021$; además, su grado de explicación es aceptable: 71.2 por ciento $\left(\mathrm{R}^{2} \mathrm{x} 100\right)$.

Un incremento en el número de miembros del hogar $(T H)$ produce el mayor impacto en el crecimiento del bienestar familiar $(B F)$, ya que de esta manera se asegura una mayor presencia de la fuerza laboral familiar en los mercados laborales, en el negocio familiar y la unidad de producción de autoconsumo. Asimismo, el monto de las transferencias de gobierno a los hogares $(T G)$ depende del número de hijos que asisten a la escuela, del número de adultos mayores y de los miembros asignados a la producción de la milpa (asociación de maíz, frijol y calabaza). La fuerza laboral de los hogares de La Purísima y San Miguel Totolapa participa en los mercados laborales de Estados Unidos y envía parte de su salario a sus hogares en su comunidad de origen (remesas internacionales, $R I$ ). La Purísima también recurre a los salarios regionales al igual que San Agustín Loxicha, la cual obtiene prácticamente de esta fuente de ingreso sus ingresos exógenos, mientras que San Miguel Totolapa se apoya más bien en remesas internas $(R N)$ (véase cuadro 2).

${ }^{3}$ Los coeficientes de regresión estandarizados $\beta_{q}$ permiten comparar de manera consistente los pesos de las variables independientes en la ecuación porque éstos son adimensionales. 
La fuerza de trabajo familiar también produce utilidades monetarias cuando los hogares poseen negocios como lo muestran: el análisis de regresión (véase cuadro 1) y el producto local bruto (véase cuadro 3). Esto concuerda con el hecho de que la mayoría de los hogares rurales en México dependen de la fuerza laboral para producir y obtener salarios y remesas (Reyes y Gijón, 2007). En las localidades de estudio, el trabajo familiar realiza el mayor aporte al producto interno bruto y el trabajo asalariado es más visible cuando las actividades son intensivas en mano de obra como ocurre con el café en San Agustín Loxicha, y la «agricultura comercial» en San Miguel Totolapa. ${ }^{4}$ La mayor proporción de los hogares rurales tiene unidades

\section{CUADRO 2}

Fuentes de ingresos de los hogares de La Purísima, San Miguel Totolapa y San Agustín Loxichaa (Porcentajes)

\begin{tabular}{lccc}
\hline & LA PURísima & SAN MIGUEL TOTOLAPA & SAN AGUSTín LOXICHA \\
\hline Población (habitantes) & 1,926 & 1,289 & 2,043 \\
Ingreso total & 100.0 & 100.0 & 100.0 \\
Ingreso local & 79.52 & 45.70 & 69.46 \\
Ingreso exógeno & 20.48 & 54.30 & 30.54 \\
Remesas & 87.74 & 90.90 & 67.59 \\
1) Internacionales & 76.39 & 36.10 & 0.00 \\
2) Internas & 1.15 & 61.90 & 1.28 \\
3) Salarios regionales & 22.45 & 2.00 & 98.72 \\
Transferencias de gobierno & 12.26 & 9.10 & 32.41 \\
\hline
\end{tabular}

aAunque la encuesta se levantó en 2008 para La Purísima y San Miguel Totolapa y en 2009 para San Agustín Loxicha, la información recabada cubre de enero a diciembre del año anterior.

b Población promedio del periodo 2005-2010 con datos del Conteo de Población y Vivienda 2005 y Censo General de Población y Vivienda 2010 del INEGI.

Fuente: Matrices de contabilidad social (MCS) de La Purísima (2007), San Miguel Totolapa (2007) y San Agustín Loxicha (2008); y estimaciones propias. La elaboración de las MCs estuvo a cargo del doctor Andrés Cruz Contreras.

${ }^{4}$ Aunque en la encuesta no se declaró la existencia de un cultivo comercial, éste fue detectado en principio a través del consumo de los hogares, el cual fue de alrededor de 40 por ciento mayor que el ingreso familiar. Los autores de este trabajo se enteraron meses después, a través de los noticiarios de la televisión. Se trata de un cultivo ilícito cuyos ingresos no fueron declarados como salarios, sino más bien se detectó a través de una inusual liquidez en una comunidad campesina que sostiene un nivel de consumo de bienes y servicios relativamente alto y sofisticado.

$134 \frac{\text { SEGUNDO SEMESTRE } 2015}{\text { MIGRACIÓN Y DESARROLLO NÚM. } 25}$ 
de producción de autoconsumo y con menos frecuencia éstas producen excedentes en pequeña escala para el mercado en parcelas de menos de cinco hectáreas. Esto se puede decir de San Miguel Totolapa y San Agustín Loxicha, en donde la producción agrícola y ganadera es predominantemente tradicional y en pequeña escala, por lo tanto, su aporte al producto local bruto (PLB) es pequeño en relación con La Purísima, en donde existen grandes productores agropecuarios con acceso a tecnología moderna (véase cuadro 3). En estas condiciones, la mayoría de los hogares recurre a fuentes complementarias de ingreso para obtener satisfactores diferentes de los productos de la milpa y del traspatio, tales como: salarios locales; ingresos exógenos (salarios regionales, remesas internas, remesas internacionales y transferencias de gobierno) (véase cuadro 2).

CUADRO 3

Producto local bruto (PLB) de La Purísima, San Miguel Totolapa y San Agustín Loxicha (Porcentajes)

\begin{tabular}{lrrr}
\hline \multicolumn{1}{c}{ ACTIVIDAD ECONÓMICA } & LA PURÍSIMA & SAN MIGUEL TOTOLAPA & SAN AGUSTíN LOXICHA \\
\hline Recolección de leña & 0.57 & 4.30 & 5.85 \\
Agricultura & 42.72 & 11.90 & 5.39 \\
Ganadería & 21.03 & 4.70 & 3.24 \\
Producción de origen animal & 2.46 & 7.10 & 4.47 \\
Manufactura y artesanías & 7.22 & 6.70 & 7.18 \\
Comercio y servicios & 26.00 & 65.30 & 73.87 \\
Total & 100.00 & 100.00 & 100.00 \\
\hline
\end{tabular}

Fuente: Matrices de contabilidad social (MCS) de La Purísima (2007), San Miguel Totolapa (2007) y San Agustín Loxicha (2008); y estimaciones propias. La elaboración de las MCs estuvo a cargo del doctor Andrés Cruz Contreras.

La ecuación [2.1] muestra que las remesas internacionales hacen la principal contribución monetaria directa al bienestar familiar. En realidad, las remesas internacionales constituyen la principal fuente de liquidez para los campesinos en comunidades rurales con acceso a las redes de carreteras estatales y nacionales. El aislamiento de las comunidades rurales reduce la migración internacional y su lugar lo ocupa la migración interna (San Miguel Totolapa) 
y los salarios regionales (San Agustín Loxicha). El aislamiento geográfico y económico de San Agustín Loxicha no ha permitido el crecimiento de las remesas internacionales, las cuales aún no son visibles a nivel de la economía local. El hecho de que las remesas internas y los salarios regionales no tengan un efecto significativo en la ecuación [2.1], a pesar de su importancia económica, indica que estas fuentes de ingreso no tienen una participación significativa en el presupuesto del bienestar familiar. Más bien, éstas pueden estar destinadas al ahorro para alcanzar metas familiares y a la inversión en negocios y producción de autoconsumo.

Los negocios familiares comerciales y de servicios hacen gran parte del valor bruto de la producción local en comunidades con relativo aislamiento. San Agustín Loxicha ha desarrollado un mercado de bienes y servicios que atiende a las localidades del municipio y San Miguel Totolapa ha concentrado sus esfuerzos en el mercado local. El comercio y los servicios hacen 73.9 por ciento del PLB en la primera localidad y 65.3 por ciento en la segunda (véase cuadro 3). El gran peso de estas actividades en las economías locales se debe a que éstas captan gran parte de la liquidez de los hogares de la comunidad mediante la venta de bienes y servicios. La Purísima no ha logrado consolidar un mercado local porque su ubicación privilegiada con respecto a las redes de carreteras estatales y nacionales la enfrenta a la competencia de importantes ciudades mercados de la región. Estas ciudades tienen un mayor auge económico que aquellas de las regiones de San Miguel Totolapa y San Agustín Loxicha. Las manufacturas en pequeña escala están presentes en las tres comunidades y las artesanías son muy escasas. El peso conjunto de estas dos actividades constituye una pequeña fracción del valor bruto de la producción local (véase cuadro 3). Sin embargo, este tipo de producción resultó ser significativo en el bienestar familiar, ya que los excedentes de sus utilidades se orientan al consumo. Los dueños de negocios familiares recurren a las cajas de ahorro, microbancos y bancos para ahorrar y obtener créditos pero también reciben créditos de prestamistas locales. El ahorro en los hogares, con negocios, tiene los mismos propósitos que en los hogares campesinos que reciben remesas. La diferencia principal radica en que los primeros ahorran montos mayores, ya que éstos pueden obtener no 
sólo remesas internacionales a través de sus miembros migrantes, sino también gran parte de la liquidez de los hogares a través de sus negocios. El ahorro en instituciones financieras y los préstamos procedentes de éstas constituyen un medio para sostener el nivel de consumo de los hogares campesinos que reciben ingresos exógenos. Asimismo, estos servicios financieros permiten alcanzar metas relativas a la compra de activos e inversiones en los negocios familiares vigentes y en nuevos negocios. Sin embargo, el ahorro restringe el consumo en el corto plazo, por lo tanto, también el bienestar familiar, a cambio de ello, un incremento en el ingreso y el patrimonio de los hogares en el largo plazo. En este sentido, la presencia del ahorro en la ecuación de regresión [2.1] con signo positivo (+) indica que éste juega un papel importante tanto en la economía familiar como en el bienestar familiar. Es decir, el balance de esta variable indica que no se está contrayendo el consumo a costa de la inversión y de conservar liquidez. Más bien, el ahorro parece haberse enraizado fuertemente en las economías familiares para sostener su nivel de bienestar, gracias a la presencia de instituciones financieras en las comunidades y en su región. Esto mismo ocurre a nivel nacional, en 2002 se estimaba que los hogares con negocios representaban 10.1 por ciento del total en las áreas rurales en México (Reyes y Gijón, 2007: 48) y su nivel de bienestar estaba asociado en general a sus utilidades de corto plazo; esto es, a reinversiones procedentes de utilidades, préstamos y ahorro, que garantizaban el funcionamiento de los negocios. En resumen, las remesas internacionales están presentes en los hogares rurales a través de sus miembros migrantes e indirectamente en los hogares con negocios.

\section{Mercado laboral regional versus migración internacional}

Se presentan los resultados de un estudio que muestra que la migración interna y la migración internacional han sido sustituidas por salarios locales y regionales. Dos condiciones han sido determinantes para lograr esta transformación. Por un lado, la relativa cercanía al mercado laboral regional y el acceso a carreteras que permiten hacer un viaje de menos de una hora, todos 
los días, y regresar con la familia después de la jornada laboral. Por otro lado, la inversión en educación ha permitido obtener atractivos salarios del mercado laboral regional e invertir los excedentes monetarios en negocios que generan tanto utilidades como empleos locales. De esta manera, la fuerza laboral no se separa de su familia como lo hacen los migrantes internos e internacionales, ni enfrentan los riesgos de cruzar la frontera en forma ilegal $y$ de ser deportados en cualquier momento.

Características de San Pablo Huitzo. Esta localizado al noroeste de la región de los Valles Centrales del estado de Oaxaca a una altitud de 1,700 m.s.n.m. Contaba con una población total de 5,519 habitantes y los hogares tenían en promedio 3.79 miembros de acuerdo con el Censo de Población y Vivienda 2010 del Instituto Nacional de Estadística, Geografía e Informática (INEGI). El río Águila tributario del río Atoyac, el cual se forma en esta localidad, recibe aguas residuales sin tratamiento procedentes de San Francisco Telixtlahuaca, ubicado aguas arriba. Por esta razón, el agua de río sólo se utiliza para el riego de cultivos. El suministro de agua entubada cubre alrededor de 50 por ciento de los hogares (De la Vega, Téllez y López, 2012), y para cubrir el déficit, los hogares han recurrido a la construcción de pozos. Como no se cuenta con un sistema de drenaje público, los hogares han construido fosas sépticas y letrinas que producen infiltraciones de materia fecal en los pozos de agua. Los resultados de la encuesta identificaron a las enfermedades de mayor incidencia que son síndrome metabólico e hipertensión. La tercera enfermedad es la artritis, que abarca todos los estratos sociales. Otras enfermedades que siguen en importancia son gastrointestinales y respiratorias. Las gastrointestinales, sin duda, están ligadas a la contaminación del agua de los pozos por material fecal. En ausencia de una red de drenaje, estas enfermedades constituyen un gasto fijo de los hogares con pozos de agua y la incidencia se eleva durante la temporada de lluvias. En cambio, el incremento de los personas con síndrome metabólico e hipertensión está asociado a una dieta rica en carbohidratos. Los hogares con menores niveles de ingreso recurren con más frecuencia al agua de pozo para cocinar y beber, mientras que los hogares con niveles de ingreso alto disponen de liquidez para pagar agua de pipa (camión cisterna) y agua purificada de garrafón. Por

$138 \frac{\text { SEGUNDO SEMESTRE } 2015}{\text { MIGRACIÓN Y DESARROLLO NÚM. } 25}$ 
esta razón, en los hogares con bajos niveles de ingreso se presentan más casos de enfermedades gastrointestinales.

Las economías familiares de San Pablo Huitzo, Oax. Los hogares de esta comunidad obtienen 90.5 por ciento de su ingreso familiar (IF), de salarios locales y salarios de la región, mientras los mercados laborales internacionales aportan solamente 0.9 por ciento; la contribución de los mercados nacionales es prácticamente insignificante e inferior al valor de la leña recolectada (véase gráfica 1). El mercado laboral local genera un monto mucho mayor en salarios $(S L)$ (28.4 por ciento) que las utilidades, juntas, de los dueños de negocios y unidades de producción agropecuarias en pequeña escala (5.7 por ciento); es apenas visible el peso en el IF de las transferencias de gobierno (TG), de las transferencias de otros hogares $(T O H)$ y los préstamos $(P r)$. Sin embargo, los dos últimos realizan una contribución significativa al bienestar familiar, como veremos más adelante.

\section{GRÁFICA 1}

Estructura del ingreso familiar de los hogares de San Pablo Huitzo, Oax., 2011

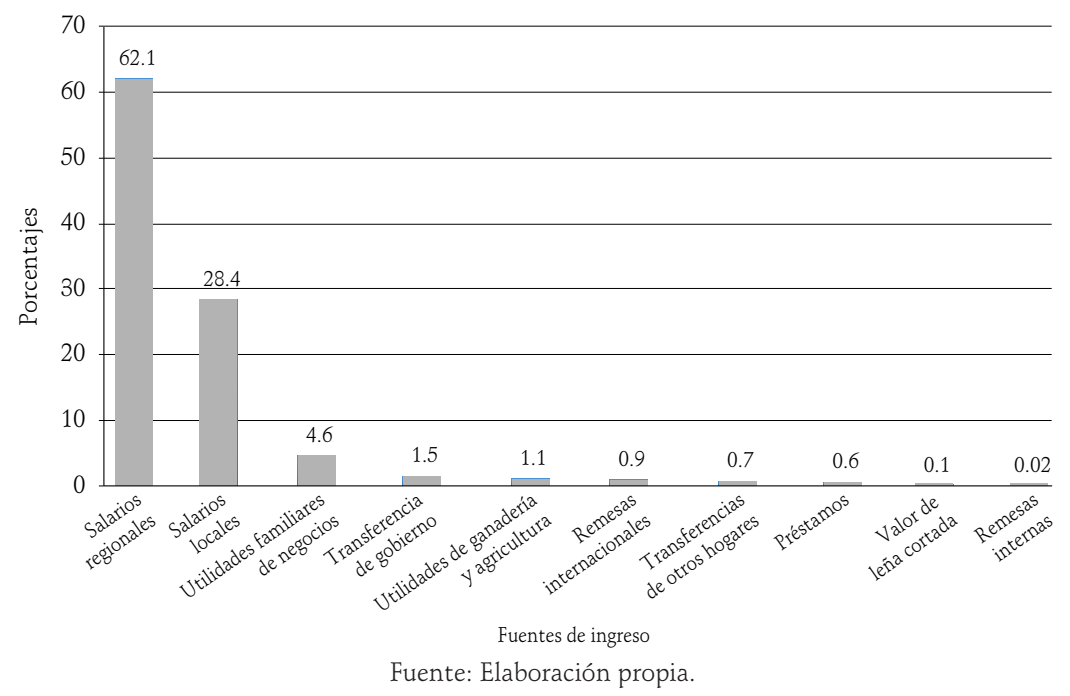

La relativa cercanía de San Pablo Huitzo a la ciudad de Oaxaca, localizada a 31 kilómetros por una carretera federal que cuenta con 15 kilómetros de 
cuatro carriles y el tiempo de recorrido es de 35 minutos; además cuenta con una autopista que reduce el tiempo por lo menos a la mitad. Esta ventaja, junto con el gasto creciente en educación de los hogares que ocupa el segundo lugar en el presupuesto de su consumo básico, han permitido cambiar gradualmente la migración tanto internacional como interna por salarios regionales y locales sin tener que cambiar de domicilio.

De acuerdo con cifras del Consejo Nacional de Población (Conapo), la migración internacional en San Pablo Huitzo disminuyó entre 1995 y 2005 con respecto a las remesas y se incrementó el número de migrantes de retorno. Sin embargo, el cálculo del índice de intensidad migratoria resultó inexacto, ya que éste se incrementó y el grado de intensidad migratoria permaneció en nivel medio (véase cuadro 4). Esto se debe a que este índice es representativo a nivel municipal y no por localidad. La tasa de migración interna de San Pablo Huitzo medida a partir de las bases de datos censales de 2000 y 2010, así como de los conteos de 1995 y 2005 del INEGI, se contrajo a un ritmo mayor en el mismo periodo (de 4.14 a 2.91 por ciento) que en la entidad (de 2.99 a 2.72 por ciento). ${ }^{5}$

\section{CUADRO 4}

Índice de intensidad migratoria, sus componentes y grado de intensidad migratoria en San Pablo Huitzo, Oaxaca, 2000 y 2010

\begin{tabular}{|c|c|c|c|c|c|c|}
\hline AÑO & $\begin{array}{c}\text { \% HOCARES } \\
\text { OUE RECIBEN } \\
\text { REMESAS }\end{array}$ & $\begin{array}{c}\text { \% HOGARES } \\
\text { CON } \\
\text { EMIGRANTES } \\
\text { EN ESTADOS } \\
\text { UNIDOS DEL } \\
\text { QUINOUENIO } \\
\text { ANTERIOR }\end{array}$ & $\begin{array}{c}\text { \% HOGARES } \\
\text { CON } \\
\text { MIGRANTES } \\
\text { CIRCULARES } \\
\text { DEL } \\
\text { QUINOUENIO } \\
\text { ANTERIOR }\end{array}$ & $\begin{array}{c}\text { \% HOGARES } \\
\text { CON } \\
\text { MIGRANTES } \\
\text { DE RETORNO } \\
\text { DEL } \\
\text { QUINOUENIO } \\
\text { ANTERIOR }\end{array}$ & $\begin{array}{l}\text { ÍNDICE DE } \\
\text { INTENSIDAD } \\
\text { MIGRATORIA }\end{array}$ & $\begin{array}{l}\text { GRADO DE } \\
\text { INTENSIDAD } \\
\text { MIGRATORIA }\end{array}$ \\
\hline 2000 & 7.77 & 5.67 & 1.55 & 0.82 & 0.00172 & Medio \\
\hline 2010 & 8.47 & 3.93 & 0.61 & 4.60 & 0.08560 & Medio \\
\hline
\end{tabular}

Fuente: Tuirán, Fuentes y Ávila (2002); Uribe, Ramírez y Labarthe (2012).

${ }^{5}$ Se calculó el porcentaje de la población de cinco años y más, total y residente en otra entidad, de los censos generales de población y vivienda por localidad de 2000 y 2010 del INEGI. Asimismo, se calcularon los mismos porcentajes a partir del conteo de población de 1995 y 2005 del INEGI.

$140 \frac{\text { SEGUNDO SEMESTRE } 2015}{\text { MIGRACIÓN Y DESARROLLO NÚM. } 25}$ 
Estas cifras constituyen una evidencia de la disminución de la migración, tanto internacional como interna, en la localidad de estudio. Por el contrario, el grado promedio de escolaridad se mantuvo por arriba del de la entidad y en ascenso entre 2000 y 2010; esto es, la escolaridad pasó de 7.69 a 8.79 años, mientras que en la entidad la escolaridad se movió de 5.62 a 6.94 años. Sin duda, el gasto promedio en educación de los hogares ha sido mayor en la localidad de estudio que el correspondiente de los hogares de la entidad. La migración internacional ha quedado como una historia documentada por los académicos que han estudiado la región Valles Centrales de Oaxaca (Conway y Cohen, 2003; Cohen et al., 2003; Cohen, 2004). Hoy San Pablo Huitzo es más que un suburbio de la ciudad de Oaxaca, ya que genera un tercio del ingreso familiar a través de salarios locales, utilidades de negocios y producción de autoconsumo (véase gráfica 1). La economía familiar no muestra problemas de endeudamiento porque los préstamos representan solamente 0.57 por ciento del ingreso familiar, monto igual al del ahorro reportado por la encuesta. Asimismo, el presupuesto del bienestar familiar que se destina al consumo básico ${ }^{6}$ representa 85.3 por ciento; de éste, 68.8 por ciento se gasta en alimentos y 12 por ciento en educación. El consumo de calidad y confort representa una pequeña porción del bienestar familiar (14.7 por ciento) y está constituido principalmente de los rubros de mejoramiento de la vivienda, comunicaciones, esparcimiento y vehículos (véase gráfica 2). Si bien se nota la influencia del patrón de consumo urbano, también se asegura el transporte particular para desplazarse al mercado laboral de la ciudad de Oaxaca. Los salarios regionales proporcionan liquidez para invertir en negocios familiares y la producción agropecuaria, de esta manera, no sólo se incrementa el ingreso familiar por medio de utilidades (5.8 por ciento), sino sobre todo se generan salarios locales (28.4 por ciento). Es decir, se induce un proceso de desarrollo local financiado por los salarios y los excedentes monetarios de la producción familiar. Los ingresos exógenos procedentes de afuera de la región (transferencias de gobierno, remesas internas

${ }^{6}$ El consumo básico está integrado por los siguientes rubros de gasto: alimentos, educación, salud, ropa y calzado, vivienda, servicios básicos de la vivienda y transporte. 
y remesas internacionales) prácticamente no tienen efecto sobre el desarrollo económico y el bienestar familiar, ya que en total apenas constituyen 4.42 por ciento del ingreso familiar. En cambio, los ingresos procedentes de la región (salarios regionales) que representan 62.1 por ciento tienen un efecto significativo sobre el bienestar familiar y la inversión en los negocios.

\section{GRÁFICA 2}

Estructura del consumo de calidad y suntuario de los hogares de San Pablo Huitzo, Oax., 2011

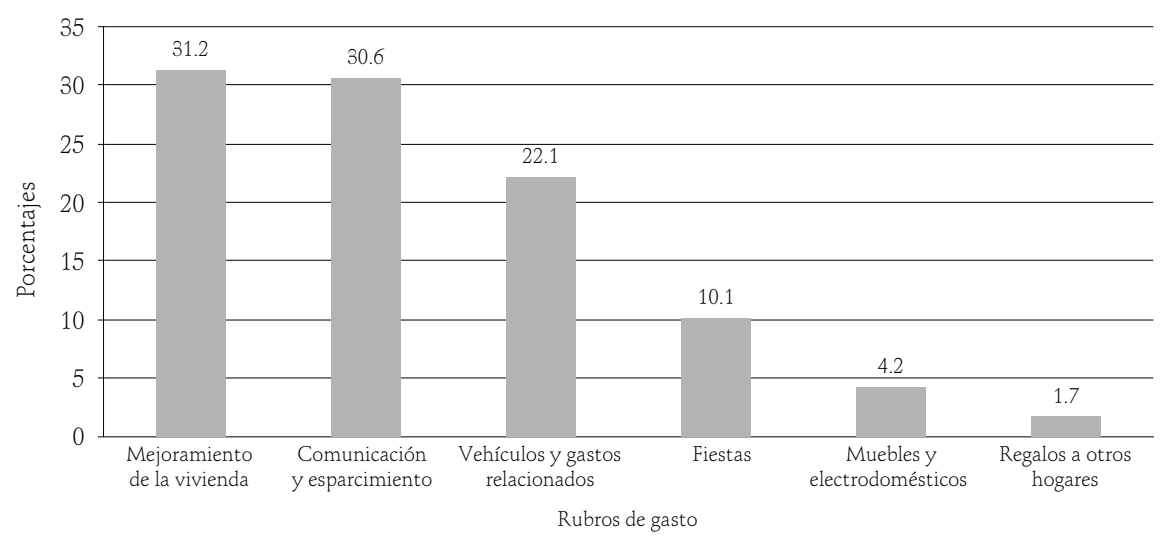

Fuente: Elaboración propia.

Modelo de economía familiar de San Pablo Huitzo con efectos ambientales y de dietas desequilibradas. Se presentan varias ecuaciones de regresión que forman el modelo. La ecuación de regresión principal [2.2.1] tiene una $\mathrm{R}^{2}$ de 0.821 y supera ampliamente la prueba del análisis general de varianza (F es significativa para $\mathrm{p}<0.000)$; las cuatro variables independientes son estadísticamente significativas de acuerdo con la prueba $t$ de student (la significación aparece debajo de cada término) y éstas se encuentran ordenadas jerárquicamente de izquierda a derecha de acuerdo con su peso en la ecuación (véase cuadro 5). 


$$
\begin{aligned}
& B F=8,592.454 E s c P+1.388 T O H+0.049 S L+0.448 U N S \\
& \begin{array}{llll}
(0.000) & (0.001) & (0.004) & (0.048)
\end{array} \\
& B F=85,703.893+0.055 S L+3.250 A R+0.441 U N S \\
& \begin{array}{llll}
(0.000) & (0.001) & (0.000) & (0.038)
\end{array} \\
& B F=0.055 S L+3.380 A R+0.448 U N S+87,534.191 O E n f+80,302.527 S M H+ \\
& \text { 87,178.507NEnf [2.2.3] } \\
& \begin{array}{lllll}
(0.001) & (0.000)(0.037) & (0.000) & (0.000) & (0.000)
\end{array}
\end{aligned}
$$

\begin{tabular}{|c|c|c|c|}
\hline & ECUACIÓN (2.2.1) & ECUACIÓN (2.2.2) & ECUACIÓN (2.2.3) \\
\hline & \multicolumn{3}{|c|}{ Coeficientes de regresión estandarizados, $\beta^{\mathrm{b}}$} \\
\hline Constante & & $85,703.893$ & \\
\hline Escolaridad promedio, EscP & 0.764 & & \\
\hline Transferencias de otros hogares, $\mathrm{TOH}$ & 0.169 & & \\
\hline Ninguna enfermedad, NEnf & & & 0.590 \\
\hline $\begin{array}{l}\text { Síndrome metabólico e hipertensión, } \\
\text { SMH }\end{array}$ & & & 0.367 \\
\hline Otras enfermedades, OEnf & & & 0.350 \\
\hline Ahorro en la región, $A R$ & & 0.367 & 0.182 \\
\hline Salario local, $S L$ & 0.153 & 0.343 & 0.172 \\
\hline Utilidades de negocios de servicios, UNS & 0.099 & 0.202 & 0.099 \\
\hline $\mathrm{R}^{2}$ & 0.821 & 0.297 & 0.845 \\
\hline $\mathrm{R}^{2}$ corregida & 0.812 & 0.27 & 0.833 \\
\hline F estadística (Anova) b & $90.869, \mathrm{p}<0.000$ & $11.132 \mathrm{P}<0.000$ & $69.833, p<0.000$ \\
\hline Grados de libertad de la regresión y total & 4 y 83 & 3 y 82 & 6 y 83 \\
\hline
\end{tabular}

\section{CUADRO 5}

Análisis de regresión de mínimos cuadrados ordinarios del bienestar familiar en San Pablo Huitzo, Oaxaca, 2011 ${ }^{\mathrm{a}}$

a Se considera una distribución $\mathrm{F}$ para la prueba de significación de la F estadística. ${ }^{\mathrm{b}}$ A menos que se indique lo contrario.

La escolaridad promedio de los hogares (EscP) es una medida del capital humano y tiene el mayor peso $\left(\beta_{1}=0.764\right)$; y con un peso, considerablemente menor, aparecen en orden descendente las transferencias recibidas de otros hogares $(T O H)$ que son una medida monetaria del capital social $\left(\beta_{2}=0.169\right)$; así como los salarios locales $(S L)\left(\beta_{3}=0.153\right)$ y las utilidades de los negocios 
de servicios (UNS) ( $\left.\beta_{4}=0.099\right)$ (véase cuadro 5). La EscP sostiene el nivel de salarios obtenidos en la ciudad de Oaxaca ( $S R$ ); los ingresos obtenidos de los negocios familiares y las transferencias de gobierno por hijos que asisten a la escuela. Los $S R$ no aparecen explícitamente, ya que éstos se destinan principalmente a la inversión en negocios familiares de servicios (UNS) y al ahorro en instituciones financieras de la ciudad de Oaxaca $(A R)$. Esta última variable aparece en ecuaciones [2.2.2] y [2.2.3], mientras que los salarios locales $(S L)$ forman parte del presupuesto del bienestar familiar, por esta razón, aparecen en las tres ecuaciones.

Cuando en la ecuación [2.2.1] se elimina EscP, ésta es sustituida por una constante y $A R$ en la ecuación [2.2.2]. Esta constante puede ser sustituida, a su vez, por tres variables independientes en la ecuación [2.2.3], que son hogares con miembros que padecen otras enfermedades (OEnf); hogares con miembros que padecen síndrome metodológico o hipertensión (SMH); y hogares que no reportaron miembros enfermos (NEnf). De estas tres variables, NEnf guarda una relación lógica y directa con el $B F$, ya que los hogares sin miembros enfermos disponen de más recursos para asignarlos a otros rubros de bienestar. En cambio, conforme se incrementan OEnfy SMH proporcionalmente a sus coeficientes de regresión no estandarizados (87,534.191 y 80,302.527, respectivamente) se reduce el presupuesto disponible para los rubros de bienestar distintos de los gastos en salud (GS). En realidad, se confunde el efecto de $O E n f$ y $S M H$ sobre el $B F$, ya que se rebasa el nivel crítico del consumo, $C_{\text {Critico }}$ y la relación $C \cong B F$ dada por [1.4] deja de cumplirse. Esto se debe a que el incremento en el consumo de los hogares va más allá del $C_{\text {Critico, }}$ ya no se refleja en el nivel de $B F$. En realidad sólo se incrementa el gasto en salud (GS), asociado al agravamiento de las enfermedades crónico-degenerativas y gastrointestinales.

Al intercambiar GS por BF se muestra evidencia de que las enfermedades gastrointestinales asociadas a contaminación de los pozos y una dieta rica en carbohidratos erosionan significativamente el presupuesto de bienestar. La ecuación de regresión [2.2.4] reportada en un trabajo previo (Celaya et al., 2013) para la localidad de estudio, se construyó a partir de 15 hogares de la 
muestra que cuentan con pozos de agua. El coeficiente de determinación múltiple $\mathrm{R}^{2}$ de esta ecuación de regresión es de 0.976 . Todos los coeficientes de regresión resultaron ser significativos al aplicar la prueba t de student ( $p<0.05)$ y desde luego también se supera la prueba del análisis general de varianza. Las variables explicativas del modelo se refieren a la contaminación de los pozos, al consumo de alimentos, a las enfermedades de mayor incidencia y a una fuente de ingresos.

$$
\begin{aligned}
& G S=1,466.46 O D+6.52 P r+0.227 C T+4,191.45 S M H \\
& \begin{array}{llll}
(0.000) & 0.000) & (0.000) & (0.049)
\end{array}
\end{aligned}
$$

El oxígeno disuelto $(O D)$ tiene el mayor peso $\left(\beta_{1}=1.378\right)$ en el gasto en salud y la relación entre el gasto en salud y esta variable es directamente proporcional; por extensión, se debe sostener una correlación significativa entre esta última variable, la demanda bioquímica de oxígeno $\left(D B O_{5}\right)$ y la demanda química de oxígeno $(D Q O)$, ya que estas variables se incrementan o disminuyen simultáneamente durante la temporada de lluvias. Mediante correlación de Pearson se pudo comprobar la relación entre $O D$ y $\mathrm{DBO}_{5}$ en la temporada de secas debido a que el coeficiente de correlación $r=0.757$ resultó significativo ( $\mathrm{p}<0.001)$; y durante la temporada de lluvias también se sostuvo la correlación entre $O D$ y $D_{B} O_{5}(r=0.657$, p < 0.008). Los hogares de bajo bienestar son los que se ven más afectados por la baja calidad del agua de pozo, porque son los que más la consumen y por ende presentan más casos de diarrea de acuerdo con la información recabada por la encuesta. Los préstamos $(P r)$ ocupan el segundo lugar $\left(\beta_{2}=0.853\right)$ y constituyen la fuente de ingreso extraordinario que más probablemente se utiliza para cubrir los gastos en salud. En tercer lugar se encuentra el consumo de cereales y tubérculos $(C T)$ con un peso significativamente menor al de las dos variables anteriores $\left(\beta_{3}=0.387\right)$. Un incremento en el consumo de estos alimentos ricos en carbohidratos, que ocupan el segundo lugar en el presupuesto de alimentos, empeora el estado de salud de las personas con síndrome metabólico e hipertensión. A propósito, la ecuación de regresión [2.2.4] incluye el síndrome metabólico y la hipertensión juntos en una sola variable, $S M H$, 
la cual resultó ser significativa $\left(\beta_{4}=0.162\right)$. Estas enfermedades juntas presentan una incidencia acumulada de 25 por ciento en los hogares de acuerdo con la encuesta.

En síntesis, el modelo establece una relación directamente proporcional entre el gasto en salud y las principales enfermedades (síndrome metabólico e hipertensión) y además una relación indirecta con enfermedades gastrointestinales a través de $O D$. Otra relación directa que sostienen es aquélla entre el gasto en salud y uno de los factores que agravan $S M H$ (dieta a base de cereales y tubérculos, $C T$ ). Finalmente, se establece también una relación directamente proporcional con la fuente de ingresos que financia el déficit en el presupuesto familiar causado por los gastos en salud (préstamos, $\mathrm{Pr}$ ).

\section{Conclusiones}

La migración interna puede ser la principal fuente de ingresos exógenos en los hogares, aun cuando las oportunidades de su fuerza laboral en los mercados laborales, local y regional son escasas, pero no sus expectativas de bienestar. Si los mercados laborales nacionales tampoco cubren tales expectativas, la migración internacional aparecerá entonces como la opción más prometedora a pesar de los riesgos que ésta implique. La migración internacional incluso puede representar una alternativa en regiones productivas en donde los intermediarios controlan el mercado.

La migración interna es una mejor opción que involucrarse con un cultivo comercial de «alto riesgo» (San Miguel Totolapa). Por el contrario, un cultivo comercial en pequeña escala como el café puede ayudar a retener la población en regiones aisladas (San Agustín Loxicha) si existe un canal de comercialización como la CEPCO que garantice un precio justo para la producción. Asimismo, será necesaria la existencia de un mercado local que satisfaga la demanda de bienes y servicios, el acceso a instituciones financieras que capten el ahorro y lo haga circular en la comunidad a través de préstamos. En estas condiciones, la fuente principal de ingresos exógenos pueden ser los salarios regionales.

$146 \frac{\text { SEGUNDO SEMESTRE } 2015}{\text { MIGRACIÓN Y DESARROLLO NÚM. } 25}$ 
El peso de la migración internacional en la economía local se puede reducir a niveles insignificantes si la localidad de referencia (San Pablo Huitzo) tiene acceso a un mercado laboral regional cercano como la ciudad de Oaxaca. Para obtener salarios más altos, los hogares han invertido en la educación de los hijos y los excedentes monetarios se han canalizado, en muchos casos, a la creación de negocios familiares. Como resultado, han emergido mercados locales que empiezan a reducir considerablemente la dependencia del mercado laboral regional y además absorben buena parte de los excedentes monetarios destinados al consumo de bienes y servicios.

La localización privilegiada de San Pablo Huitzo la tiene también La Purísima, pero los altos niveles de delincuencia del estado de Michoacán hacen más atractiva la migración internacional, la cual dispone de redes construidas desde más de un siglo.

Los especialistas en migración y desarrollo buscan afanosamente estrategias para reducir o eliminar la migración a través de proyectos productivos financiados con remesas. En ese sentido, la lección de este trabajo es que la inversión en educación puede ser una buena opción si se tiene acceso a mercados laborales regionales relativamente cercanos. Otra opción es contar con un cultivo comercial e invertir sus excedentes monetarios en negocios comerciales y de servicios orientados a la población local. Así, se fortalecerán tanto las economías familiares como la economía local. En el otro extremo se encuentran las utilidades de actividades comerciales que se desvanecen por las distorsiones del mercado causadas por los intermediarios. Otro caso similar son las utilidades y los salarios asociados a un cultivo comercial de «alto riesgo» que apoyan el desarrollo de un mercado local; sin embargo, los niveles de bienestar de los hogares son inestables y la integridad física de la fuerza laboral se encontrará bajo riesgo permanente.

En este contexto, el espejismo de las remesas internacionales sostenido por el mercado laboral estadounidense que demanda principalmente mano de obra de baja calificación, se confunde con el de las utilidades y salarios de actividades de «alto riesgo». Sobre todo en estos tiempos de crisis económica recurrente, el gobierno de Estados Unidos trata de parar a toda costa la migración indocumentada, pero su sociedad no reduce el consumo de produc- 
tos asociados a los cultivos ilícitos procedentes de la frontera sur. Es decir, la «mano invisible» en ese país lo mismo incentiva los cultivos ilícitos que la inmigración masiva de la mano de obra indocumentada.

Finalmente, cuando se ha logrado sustituir a las remesas internacionales por los salarios regionales y locales, aparecen nuevos demonios que surgen de la contaminación que producen los hogares y de las dietas desequilibradas. Por consiguiente, el bienestar familiar no depende solamente y de manera directa del ingreso familiar y de las capacidades que remarca Amartya Sen, sino también de manera inversa de la contaminación y de los malos hábitos de alimentación. Sin embargo, el Estado mexicano no ha mostrado capacidad para revertir estos problemas mediante la construcción de redes de drenaje público para todos los hogares, ni para orientar a la población sobre el consumo saludable de alimentos. En cambio, los servicios financieros empiezan a constituir una pieza clave de las economías familiares rurales, como lo muestran los resultados de la aplicación del modelo de bienestar familiar. Así, la economía de mercado está logrando un enraizamiento profundo en las áreas rurales de México y se está creando un mercado financiero rural.

\section{Bibliografía}

ARANDA, Josefina y Carmen Morales (2002), «Evaluación de los beneficios actuales y el potencial para el combate a la pobreza de la participación en redes de comercio justo de café en la Coordinadora Estatal de Productores de Café de Oaxaca», Fair Trade Research Group, en http://www.colostate.edu/Depts/Sociology/ FairTradeResearchGroup/doc/cepcoreportfinal.pdf

Benítez Ávila, Isabel Selene (2013), «Evaluación de un modelo de desarrollo sustentable mediante análisis socioeconómico y de la contaminación del cultivo de maíz por 3 metales pesados en la comunidad de San pablo Huitzo, Oaxaca», tesis de licenciatura, Oaxaca, FCO, UABJO.

Boltvinik, Julio (2003), «Tipología de los métodos de medición de la pobreza. Los métodos combinados», Comercio Exterior, vol. 53, núm. 5.

$148 \frac{\text { SEGUNDO SEMESTRE } 2015}{\text { MIGRACIÓN Y DESARROLLO NÚM. } 25}$ 
Celaya Vásouez, Hugo (2013), "Construcción de un modelo de salud, medio ambiente y economía familiar», tesis de licenciatura, Oaxaca, FCO, UABJO.

Celaya V., Hugo, A. Sylvia Gijón C., G. Rafael, M. Reyes, L. Juan, M. Bautista, I. Selene A. Benítez, María de J., H. Pacheco (2013), «Desarrollo sustentable, bienestar y salud en San Pablo Huitzo, Oaxaca, Oaxaca», Memoria del $9^{\circ}$ Congreso Nacional de Amer: Crisis Civilizatoria en el México Rural, pp. 1-22.

Cervantes, Virginia y Ana Paula de Teresa Ochoa (2004), «Historia del uso del suelo en la comunidad de Zoyatlán, Guerrero", Alteridades, vol. 14, núm. 27.

CoHen, Jeffrey (2004), The Culture of Migration in Southern Mexico, Austin, University of Texas Press.

Conen, Jeffrey, A. S. Gijón-Cruz, R. G. Reyes-Morales y G. Chick (2003), «Understanding Transnational Processes: Modeling Migration Outcomes in the Central Valleys of Oaxaca, Mexico», Field Methods, vol. 15, núm. 4.

Conway, D. y J. H. Cohen (2003), «Local Dynamics in Multilocal, Transnational Spaces of Rural Mexico: Oaxacan Experiences», International Journal of Population Geography, vol. 9, núm. 2.

De la Vega Estrada, Sergio, Yolanda Téllez Vázquez y Jorge López Ramírez (2012), Índice de marginación por localidad 2010, México, Consejo Nacional de Población.

Durand Alcántara, Carlos, G. Cruz Velásquez y María de Jesús Rodríguez (2006), «La cuestión agraria en Mesoamérica. El caso de los pueblos indios de Guerrero, México», Memoria del VII Congreso Latinoamericano de Sociología Rural, Quito, 20-24 de noviembre.

Instituto Nacional para el Federalismo y el Desarrollo Municipal (Inafed), Gobierno del Estado de Michoacán (2009), Álvaro Obregón, Estado de Michoacán. Enciclopedia de los municipios de México, en http://www.e-local.gob.mx/wb2/ELOCAL/ EMM_michoacan

(2009), Huamuxtitlán, Estado de Guerrero, Enciclopedia de los municipios de México, en http://www.e-local.gob.mx/wb2/ELOCAL/ELOC_Federalismo (2009), Agustín Loxicha, Estado de Oaxaca, Enciclopedia de los municipios de México, en http://www.e-local.gob.mx/wb2/ELOCAL/ELOC_Federalismo Knoke, David, George W. Bohrnstedt y Alisa Potter Mee (2002), Statistics for Social Data Analysis, Estados Unidos, Wadsworth/Thomson Learning.

Pacheco Hernández, María de Jesús (2013), «Evaluación de un modelo de bienestar a través del análisis parasitológico de suelos agrícolas y estudio socioeconómico de las unidades domésticas de San pablo Huitzo, Etla, Oaxaca», tesis de licenciatura, Oaxaca, FCO, UABJO. 
Reyes Morales, Rafael G. et al. (2013), "Modelo teórico de desarrollo local sustentable y comprobación en una comunidad rural oaxaqueña», Negocios y Desarrollo, núm. 1.

Reyes Morales, Rafael G. y Alicia Sylvia Gijón Cruz (2007), «Desarrollo rural, migración internacional y escasez de mercados financieros en México", Trace, núm. 52.

(2011), «Bienestar y remesas internacionales de los hogares rurales en México», Memoria del IV Congreso RIMD: Crisis Global y Estrategias Migratorias, Quito, Flacso, 18-20 de mayo.

(2012), «El modelo de bienestar familiar, un instrumento efectivo para el análisis del desarrollo de las localidades rurales de México», Memoria del 1er Congreso Iberoamericano de Desarrollo Regional/17 Encuentro Nacional de Desarrollo Regional, México, Amecider, UNAM-IIE.

Salinas Callejas, Edmar (2000), "Regulación y desregulación en el caso del café», Análisis Económico, vol. 15, núm. 31.

SÁnchez Serrano, Evangelina (2003), «La certificación agraria en la montaña de Guerrero y las comunidades indias: problemas y perspectivas», Revista Mexicana de Ciencias Políticas y Sociales, vol. XLVI, núm. 188-189.

Sen, Amartya (1999), Development as Freedom, Nueva York, Knopf.

Strauss, John (1986), «Theory and Comparative Statistics of Agricultural Household Models: A General Approach», en I. J. Singh, L. Squiere y J. Strauss (eds.), Agricultural Household Models: Extensions and Applications, and Policy, Baltimore, Johns Hopkins University Press.

TAYlor, J. E. y A. Yúnez-Naude (1999), Education, Migration and Productivity: an Analytic Approach and Evidence from Rural Mexico, Development Centre of the Organisation for Economic Co-operation and Development.

Tuirán, Rodolfo, Carlos Fuentes y José Luis Ávila (2002), Índices de intensidad migratoria México-Estados Unidos, 2000, México, Consejo Nacional de Población.

Uribe Vargas, Luz María, Telésforo Ramírez García y Rodrigo Labarthe Álvarez (2012), Indices de intensidad migratoria México-Estados Unidos 2010, México, Consejo Nacional de Población. 